\title{
THE POTATO AS FOOD
}

"T HE United Kingdom has just had the largest crop of potatoes for many years, and unless the consumption is increased beyond the present level there will be a large surplus at the end of the season. . . . Potatoes are one of the best foods grown, for they are both energy-producing and protective." (The Times, January 15, 1941, quoting the Ministry of Food.)

One is perhaps prompted to query whether this forecasts an increased surplus over this year, when the tonnage of potatoes which the public will not be able to consume reaches almost astronomical figures. Moreover, what does this somewhat loose expression "energy-producing and protective" mean? It therefore seems apposite to consider whether the discussion on the potato as food, which took place a few weeks ago, helps to assess the value of the potato; the meeting was held under the auspices of the Nutrition Panel of the Food Group of the Society of Chemical Industry, and three papers were presented and discussed, concerned respectively with the biology (Dr. Redcliffe Salaman), the chemical constitution (Dr. L. H. Lampitt and Mr. N. Goldenberg), and the nutrition value (Dr. Harriette Chick) of the potato. All authors agreed on the importance of the potato as an article of diet; but all three papers also indicated the lack of scientific knowledge and the desirability of well-planned and comprehensive experiments. This point was stressed particularly by Dr. Salaman and by Dr. Lampitt.

Dr. Salaman has made a detailed study of the history of the potato, and those who have read his various publications on this matter must recognize how much science owes to him for unravelling a very tangled skein. A proper understanding is essential if progress is to be made.

It is possible that the potato breeder is at the end of his tether in respect of improving the varieties from the available material, and one has heard with great satisfaction of the collection of potatoes at Cambridge made during the years immediately preceding the War from parts of South America, including the High Andes. One hopes that these experiments will not suffer the fate of so many Government schemes of research and be jettisoned on the score of expense. The importance to the potato breeder of new varieties, the introduction of 'new blood', cannot be over-estimated. If it is agreed that more potatoes still should be grown, the importance of virus-free seed has been amply demonstrated. Possibly the solution of the problem is not quite so simple as expounded by Dr. Sala- man ; in fact, the Board of Agriculture appears (from one of the speakers in the subsequent discussion) to be somewhat sceptical of the virus-free theory. However, as a working hypothesis the advantage of stock not affected by the potato virus cannot be denied.

Moreover, it has already been pointed out that, with attention to peeling and 'eyeing', an increase of more than 33 per cent in potatoes 'ready-toeat' is possible in Great Britain without increasing the acreage of land under potato crop ("The Nation's Larder"). Whilst it is recognized that the careful peeling necessary to achieve this increase is probably outside the scope of the housewife, an increase of 20 per cent should be capable of realization. Obviously, the greatest claim that can be made for potatoes is that they are home grown, and that valuable shipping space might be released if the amount of grain to be brought from overseas could be reduced. The $\frac{3}{4} \mathrm{lb}$. per diem for each head of the population would not be excessive. There are many countries where this figure is exceeded. An example is Germany, where for years previous to the outbreak of the War the use of potatoes was enforced as a diluent for wheat flour. It is, in fact, to the potato that Governments lead the nations when measures of economy are necessary.

This makes it all the more difficult to understand the paucity of basic knowledge on the chemistry of the potato. The variability of the tuber and the number of factors involved, make it essential that all experiments be planned on a large scale so that a statistical study can be effectively made. Some years ago an extensive investigation of certain factors was undertaken by the Rothamsted Experimental Station, and for two or three years previous to 1929 .

It is a notable fact that the consumption of potatoes declines as the so-called 'standard of living' rises. Dr. Salaman thinks, too, that the craze of 'slimness in women' is a contributory factor, but our observations would lead us to suggest that this 'fear of the potato' is not confined to women; many of those of the male sex who bow down to the god of physical fitness shun the potato.

The Potato Marketing Board had a most comprehensive study of the 'blackening' of potatoes in progress; this investigation was abandoned, however, presumably as a measure of economy, a decision of a Government department that all should deplore, for in certain seasons this 'blackening' effect causes great loss to the nation. 
The survey of the literature (J. Soc. Chem. Ind., $59,45,748$ ) with its reference to some 250 papers, seems to prove that very few of the statements that have been made have been definitely corroborated. It was pointed out that many of the observations recorded are either fragmentary or directed towards some isolated problem. The nonstatic character of the potato itself is to some extent responsible for the lack of uniformity of the results obtained. Variety, age and condition of growth are all major factors in the composition of the potato, and when to these are added the fact that the potato is not homogeneous, and that the greater number of workers have failed to state whether their analyses were conducted on peeled or unpeeled tubers, the chaotic condition of the data is to be understood. Lack of details of the method used in preparing a sample for examination is one of the most common failings in the description of much of the work on 'natural' products in the food world, and it is a point of interest that at meetings of the nature of the one in question, attempts to summarize present knowledge demonstrate the great importance of such elementary precautions.

Meetings of this nature are of importance, if only that in these times they make it possible for the 'fringe' scientific worker to evaluate the dicta, or even the advertisements of the Minister of Food.

Dr. Chick quoted figures which give some information relative to the 'energy'-producing' value of the potato. $100 \mathrm{gm}$. of potatoes baked in the skins is equivalent to 113 calories, whilst $100 \mathrm{gm}$. of white bread is equivalent to 260 calories ; in other words, the potato as prepared in this manner has a caloric value less than half that of the same weight of bread. Of the mineral elements, the importance of which in nutrition cannot be denied, potatoes are less effective than bread.

As 'protective' food, an important effect of potatoes is to provide or supplement the B-vita. mins. Vitamin $B_{1}$ (aneurin) is probably present to an extent of about one quarter of that of wholemeal bread, for as Dr. Chick stated, the aneurin contents of potatoes and of wholemeal bread are approximately equal when the dry weights of the foods are taken into account. Unfortunately, little reliance can be placed on the scattered results in the literature concerning the other B-vitamins.

The importance of the potato as an antiscorbutic has also to be considered. The fact that scurvy has appeared in countries largely dependent on the potato for food, when the crop has failed, is a significant fact, and evidence was forthcoming in the discussion of the papers that the tuber is a necessary source of ascorbutic acid. If, however, full advantage is to be taken of the vitamin C content of potatoes, then the water in which the tubers are boiled should be consumed, for there is considerable loss of ascorbutic acid by diffusion into the water. Here the nutritionist and the gourmet are in agreement, for M. André Simon, who was chairman of the meeting, remarked on the value of the potato water in the preparation of soups and sauces.

\title{
DIET IN RELATION TO DENTAL CARIES*
}

\author{
By Prof. E. V. McCollum, \\ JoHn Hopkins UnIVERSITY
}

$\mathrm{T}$ $\mathrm{HE}$ carious lesion in a tooth is caused by acid decomposition of the enamel, and afterwards the dentine, associated with proteolytic destruction of the organic substance of the tooth. Caries of the teeth is restricted to man and other animals which eat liberally of carbohydrate-containing foods. Carnivorous man and animals do not suffer from this disease. Dental caries does not attack the surfaces of teeth indiscriminately, but occurs only at such sites as favour the lodgment of food residues, as in pits or fissures, or on surfaces of the enamel which harbour mucinous plaques. In such

* Substance of a paper read on September 18 at the Bicentennial Conference, University of Pennsylvania. sites acid is formed by fermentation of carbohydrate by micro-organisms, and is protected against being washed away by saliva or by neutralization by salivary alkalinity.

Throughout the Americas and Europe, and in most other temperate or torrid parts of the world, almost everyone eats liberally of carbohydrates, so the pabulum for feeding micro-organisms of every kind associated with fermentations is present in abundance at times in every mouth. Yet there is a great variation in the susceptibility of different people to dental caries. Numerous investigations have been devoted to attempts to discover why this great variation exists. Bunting and his 